\title{
CASSAVA PROCESSORS' AWARENESS OF OCCUPATIONAL AND ENVIRONMENTAL HAZARDS ASSOCIATED WITH CASSAVA PROCESSING IN SOUTH-WESTERN NIGERIA.
}

$$
\text { Oyegbami } A^{* 1}, \text { Oboh } G^{2} \text { and } * O \text { Omueti }^{1}
$$

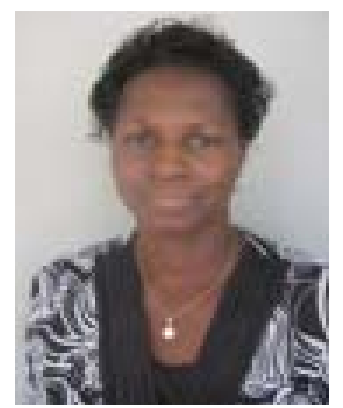

A Oyegbami

*Corresponding author email: titi_oyegbami@yahoo.com

${ }^{1}$ Institute of Agricultural Research and Training, Obafemi Awolowo University, Moor Plantation, Ibadan, Nigeria

${ }^{2}$ Department of Biochemistry, Federal University of Technology, Akure, Nigeria. 


\section{ABSTRACT}

The processing of this popular root tuber into different products (gari, fufu, pupuru) is not without hazards both to the environment, the processors, and even the consumers. This study, therefore, investigated cassava processors' awareness of occupational and environmental hazards associated with and factors affecting cassava processing in three states - Oyo, Ogun and Ondo in South-western Nigeria. A total of 380 cassava processors were purposively and randomly selected from the three states. Data were collected through the use of structured interview guide using the participatory and focus group approach with the assistance of experienced enumerators. The data were analysed using frequency counts and percentages. Results from the study showed that majority $(68.9 \%)$ of the respondents involved in cassava processing were females, $65.7 \%$ are between the ages of 31-50 years which means that they were still in their active age, $48 \%$ have between 4-6 persons as household size, $64.2 \%$ had one form of education or another which is a good indicator of their level of understanding especially where a technology involves a little technicality. Another $55.5 \%$ of the respondents took cassava processing and marketing as their primary occupation. A larger percentage $(74.5 \%)$ of the respondents indicated that the Agricultural Development Programme (ADP) is their source of information. The result also showed that processor's awareness of occupational hazards associated with the different stages of cassava processing vary because their involvement in these stages also varies. They were also aware of environmental hazards associated with cassava processing. Majority (97.7\%) of the respondents combined conventional and modern methods of cassava processing. Majority of the respondents also complained of lack of water $(78.4 \%)$, lack of effective channel for cassava effluent $(64.5 \%)$, lack of labour $(80.3 \%)$ and unstable price of cassava products $(70.3 \%)$ as major factors affecting cassava processing in the study area. It is, therefore, recommended that for proper channeling be made for cassava effluent, cassava peels should be sun-dried and used as livestock feed, government and the community should provide a borehole or a deep well as this will improve cleanliness of the environment cassava products. Key stakeholders can also participate in the design of processing site from inception so as to reduce the problems faced by cassava processors during processing.

Key words: Cassava-processors, awareness, hazard, processing, Nigeria 


\section{INTRODUCTION}

Cassava (Manihot esculenta Crantz) is a perennial vegetatively propagated shrub and is one of the most important food crops grown in Africa [1]. It is high yielding and drought resistant and with improved pest management practices, its high yielding capacity could be sustained [2].Cassava is grown for use as food in more than thirty nine African countries [3]. Based on the above, cassava has become economically important in several tropical countries where the carbohydrate content of its enlarged root in diversified forms is consumed in most African countries, including Nigeria. Food products from cassava include gari (fermented and roasted granules) fufu (fermented and steamed cooked), pupuru (fermented smoked dried balls and also gelatinized), lafun (fermented, sun dried flour and then gelatinized for the table). Cassava has been found to be a great giant that fights hunger and provides earnings for the farmer. Thus, in terms of food security for Nigeria and other African countries cassava has its place. It is then obvious that cassava processing must be given high consideration because of its inseparability from man and animals especially in the developing countries where it is the cheapest food used to combat hunger [4].

The processing of this popular root tuber into the many products enumerated earlier has hazards to the environment, the processors, and even the consumers. It is a known fact that the well-being of man depends not only on the food he eats but the effect of his environment on him. Therefore, the interaction between the environment and man's activities should be of concern and should be adequately addressed. The safety of the processors, the food products and the environment should be considered in crop processing. Cassava processing activities have both positive and negative effect on the environment, vis-à-vis the environment's response either positive or negative to the activities of man. For example, littering of the environment with refuse destroys the freshness, cleanliness and aesthetic value of such environment. The environment responds to this negative effect in form of stenches and microbial load, which may be injurious to man's health [4].

The enlarged roots of cassava contain huge amount of cyanogenic glucosides (linamarin and lotaustralin) in the outer covering and in the thicker leathery parachymatrous inner covering [5]. The glucosides are not the direct agent of toxicity in cassava, but its hydrolytic products, hydrocyanic which can be poisonous to human and animals when eaten in large quantities [5]. Attendant hazards arising from cassava processing are associated with the different processing steps that lead to food products obtained from cassava. The different steps include harvesting, peeling, grating, dewatering, fermentation, roasting or drying and finally packaging for sales [6].The two major wastes generated during cassava processing namely peels and the effluents had been identified to cause high economic damages to vegetation and structures [7]. They also bring about infestation of insects which can later lead to disease-infection in both man and animals. The most widely adopted method (traditional method) of cassava processing has also led to various pathology ranging from general body aches, pains and fatigue, and high body temperature due to smoke in the roasting environment [8]. 
This study, therefore, investigated processors' awareness of occupational and environmental hazards associated with cassava processing; it also identified the different methods adopted by respondents for cassava processing as well as factors affecting cassava processing. The study finally recommended ways of reducing these hazards.

\section{METERIALS AND METHOD}

The study was conducted in three states: Oyo, Ogun and Ondo in South-western Zone of Nigeria. This zone is also known to be one of the major cassava growing areas in the country. A purposive random sampling method was used to select 150 processors from each state to make a total of 450 cassava processors in the 3 states. In each state, 9 processing centres were purposively selected: 3 processing centers in each town and 3 towns in each state to make a total of 27 processing centers in the 3 states.

Primary and secondary data were collected for the study. In primary data collection, a validated interview guide was used to obtain information from the respondents while secondary data were obtained through journals, books and bulletins. Participatory rural appraisal method and focus group discussion method were also used. Out of the 450 questionnaires, 380 were returned and therefore used for drawing data for the study. The data were subjected to descriptive analyses, which involved the use of tables, frequency counts and percentages.

\section{RESULTS}

The sample for this study was 380 cassava processors of which $68.9 \%$ were female and $31.1 \%$ were male (Table 1). Majority $(65.7 \%)$ were between the ages of $31-50$ years and $48 \%$ of the respondents have between 4-6 persons as household size. Table 1 also indicates that $64.2 \%$ of the respondents had one form of education or another. Cassava processing and marketing were the primary occupation of more than half $(55 \%)$ of the respondents, $19.7 \%$ were involved solely in farming, $17.4 \%$ were into trading while $7.9 \%$ were involved in all the activities (farming, cassava processing and marketing, and trading) as their primary occupation. The Agricultural Development Programme (ADP) is the source of information to $74.5 \%$ of the respondents.

Majority (97.65\%) of the respondents interviewed combined conventional and modern methods of cassava processing. For example, some stages in cassava processing like grating, dewatering, drying (in some cases) and sieving were done using modern tools like hydraulic press for dewatering, modern grater for grating, and dryer with chimney for garification. Very few $(2.4 \%)$ of the respondents used purely conventional methods of cassava processing (from peeling stage to the final end-product). None of the respondents used purely modern methods of processing since the technology in this regard was still being developed (Table 2). 
Almost all the respondents interviewed were aware of cuts and bruise (100\%), aches and pains $(91.1 \%)$, fatigues $(77.1 \%)$, dermatitis/skin irritation $(100 \%)$, and eye irritation $(87.1 \%)$, as occupational hazards associated with the different stages of cassava processing. The results in Table 4 indicate that $94.2 \%$ of the respondents interviewed were aware of the damage caused by cassava effluent especially to buildings and vegetation. All (100\%) of the respondents were aware of the stench that emanates from the heap of peels and effluent. Only $2.6 \%$ were aware of the insect and disease infestation. All (100\%) of the respondents were not aware of the health hazards that result from burning of cassava peels.

Table 5 shows that more than half $(78.4 \%, 70.3 \%$ and $64.5 \%$, respectively) of the respondents identified lack of water, unstable price of cassava products and lack of effective channel for cassava effluent as major constraints in cassava processing. Another $44.5 \%$ and $80.3 \%$ of the respondents also identified lack of effective disposal method for cassava peels and lack of labour as major constraints in cassava processing while some of the respondents did not see these as a constraint.

\section{DISCUSSION}

The results from this study showed that females were more involved in cassava processing than males. This showed that women played a key role in family farm sector and were the principal producers of its subsistence agricultural production and also the prime producers of staple food; this corroborates the study of Adebayo and Salahu [9]. Also, majority $(65.7 \%)$ of the respondents (cassava processors) were within the ages of 30-50 years which simply means that they were within the active age of productive labour. About half (47.9\%)of the respondents interviewed had between 4-6 persons as household size, which might be an advantage if every member of the household constituted the labour force by assisting in cassava production and processing. High level of education of some of the respondents was a good indicator of their level of understanding especially where a technology involved a complex technicality. The Agricultural Development Programme (ADP) is the source of information to $74.5 \%$ of the respondents. This indicates that the ADPs are really carrying out their duties since they are the only arm of government charged with the responsibility of transferring improved technologies to farmers.

The respondents' combination of both conventional and modern methods of cassava processing showed that there was advancement in cassava processing methods and processors had adopted improved methods of processing introduced to them. The few processors that used purely conventional method of cassava processing were those that process cassava for home consumption alone and not for commercial purpose.

Majority of the respondents interviewed were aware of the occupational hazards such as cuts/bruise (100\%), aches and pains (91.1\%), fatigues $(77.1 \%)$, dermatitis (100\%), which could occur anywhere from peeling stage to the final stage of frying/cooking. These are manifestations of physical hazards, which occur as a result of the processing. Since man's concern especially in the face of poverty is to combat hunger

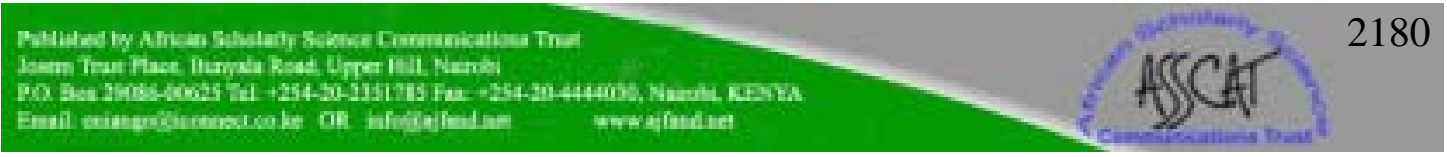


through production and consumption of food, he could be totally unaware of the dangers associated with the activities involved in cassava processing.

Furthermore, the result from this study also showed that processors were aware of the dangers posed by effluent from cassava to the environment such as destruction of buildings and vegetation as these were visible during interview. The information gathered revealed that there were some problems that affected cassava processing; these problems were the respondent's personal opinion of the constraints in cassava processing. Majority of the respondents identified lack of water $(78.4 \%)$, unstable price in cassava products $(70.3 \%)$, and lack of effective channel for cassava effluent (64.5\%) and lack of effective disposal method for cassava peels and effluent (44.5\%) as major constraints in cassava processing.

\section{CONCLUSION AND RECOMMENDATION}

It is established from this study that cassava processors were aware of occupational and environmental hazards associated with cassava processing but were ignorant of these hazards. Furthermore, it appears that this aspect of an agricultural system has been neglected to the detriment of the society at large in terms of good health, profit margin and quality of product. The processors had marks of occupational hazards such as cuts, bruises, fatigue, aches and dermatitis associated with their trade but had no knowledge of the extent of dangers posed on them under continuous exposure. In terms of cassava processing, the hazards emanating from cassava waste continuously result in losses and destruction of crops, vegetation and aesthetic value of the environment. Adoption of integrated system of waste disposal (peels and effluent) is ideal and a much desired control management of hazards associated with cassava processing. In addition to this, awareness campaign of existence of such hazards and the use of protective clothing cannot be overemphasized. A friendly environment is the determinant of wealth, safe and healthy living of man.

Consequently, the following recommendations are made for government, stakeholders and processors for economically viable trade and hazard-free cassava processing.

1. Government should provide bore-hole/deep well as this will improve cleanliness of the environment as well as cassava products.

2. Government should participate in the design of processing sites from inception.

3. Proper channeling should be made for cassava effluent (waste water from cassava) into septic tank where it can be recycled and used for other purposes.

4. Cassava peels should be sun-dried and used as livestock feed.

5. Cassava processors should also wear protective coverings such as hand gloves, overall, mouth/nose hood, eye goggles as these will protect them and reduce occupational hazards.

6. Government should subsidize the cost of protective wears in order to encourage the use such wears. 


\section{ACKNOWLEDGEMENTS}

Oyegbami, A and Omueti, O are Research Fellow and Research Professor, respectively associated with the Institute of Agricultural Research and Training, Moor Plantation, Ibadan, Oyo State, Nigeria while Oboh, G is a Senior lecturer in the department of biochemistry, Federal University of Technology, Akure, Ondo State, Nigeria. 


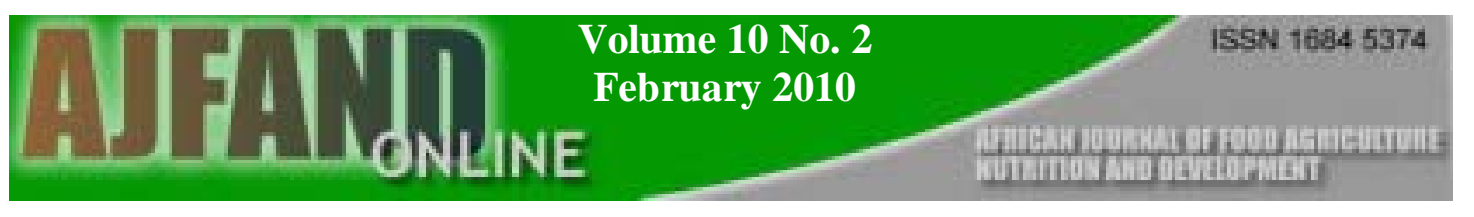

Table 1: Demographic characteristics of respondents

$\mathrm{n}=380$

\begin{tabular}{|c|c|c|}
\hline Parameter & Frequency & Percentage \\
\hline $\begin{array}{l}\text { Sex } \\
\text { Male } \\
\text { Female } \\
\end{array}$ & $\begin{array}{l}118 \\
262\end{array}$ & $\begin{array}{l}31.1 \\
68.9\end{array}$ \\
\hline $\begin{array}{l}\text { Age } \\
<30 \\
31-40 \\
41-50 \\
51-60 \\
>60 \\
\end{array}$ & $\begin{array}{l}79 \\
146 \\
105 \\
36 \\
14\end{array}$ & $\begin{array}{l}20.8 \\
38.4 \\
27.3 \\
9.5 \\
3.7 \\
\end{array}$ \\
\hline $\begin{array}{l}\text { Household size } \\
1-3 \\
4-6 \\
>6\end{array}$ & $\begin{array}{l}78 \\
182 \\
120 \\
\end{array}$ & $\begin{array}{l}20.5 \\
47.9 \\
31.6 \\
\end{array}$ \\
\hline $\begin{array}{l}\text { Educational status } \\
\text { No formal education } \\
\text { Adult education } \\
\text { Primary education } \\
\text { Secondary education } \\
\text { Tertiary education }\end{array}$ & $\begin{array}{l}136 \\
40 \\
119 \\
75 \\
10\end{array}$ & $\begin{array}{l}35.8 \\
10.5 \\
31.3 \\
19.7 \\
2.6\end{array}$ \\
\hline $\begin{array}{l}\text { Primary occupation } \\
\text { Farming } \\
\text { Cassava processing and } \\
\text { marketing } \\
\text { Trading } \\
\text { All of the above }\end{array}$ & $\begin{array}{l}75 \\
207 \\
66 \\
30\end{array}$ & $\begin{array}{l}19.7 \\
55.0 \\
17.4 \\
7.9\end{array}$ \\
\hline $\begin{array}{l}\text { Source of information } \\
\text { ADP } \\
\text { Radio } \\
\text { Television } \\
\text { Friends and neighbours }\end{array}$ & $\begin{array}{l}283 \\
53 \\
21 \\
24\end{array}$ & $\begin{array}{l}74.5 \\
13.9 \\
5.5 \\
6.3\end{array}$ \\
\hline
\end{tabular}


Table 2: Methods used for cassava processing $\mathrm{n}=380$

\begin{tabular}{|l|l|l|}
\hline Methods & Frequency & Percentage \\
\hline Purely conventional & 9 & 2.4 \\
Purely modern & - & - \\
Conventional with modern & 371 & 97.6 \\
\hline
\end{tabular}

Table 3: Processors awareness of occupational hazard associated with cassava processing

$\mathrm{n}=380$

\begin{tabular}{|l|l|l|}
\hline Associated hazards & Aware & Not aware \\
\hline Cut/bruise & $380(100.0)$ & - \\
Fatigue & $346(91.1)$ & $34(8.9)$ \\
Dermatitis/shin irritation & $380(100.0)$ & $86(22.9)$ \\
Eye irritation & $331(87.1)$ & - \\
\hline
\end{tabular}

NOTE: Figures in parenthesis are in percentages

* Multiple response given 


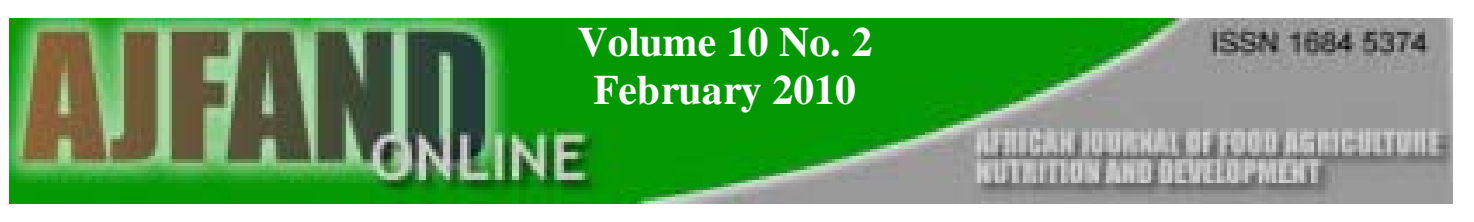

Table 4: Awareness of environmental hazards associated with cassava processing $\mathrm{n}=380$

\begin{tabular}{|l|l|l|}
\hline Environmental hazards & Aware & Aware \\
\hline Damage to buildings by effluent & $358(94.2 \%)$ & $22(5.8 \%)$ \\
Stench from heap of peels/effluent & $380(100.0 \%)$ & - \\
Possible insect and disease infestation & $10(2.6 \%)$ & $370(97.4 \%)$ \\
Health hazard that result from burning of cassava peels & - & $380(100.0 \%)$ \\
\hline
\end{tabular}

NOTE: Figures in parenthesis are in percentages

* Multiple response given

Table 5: Constraints in cassava processing

$\mathrm{n}=380$

\begin{tabular}{|l|l|l|l|}
\hline \multicolumn{1}{|c|}{ Constraints } & \multicolumn{1}{|c|}{$\begin{array}{c}\text { Major } \\
\text { constraint }\end{array}$} & \multicolumn{1}{c|}{$\begin{array}{c}\text { Minor } \\
\text { constraint }\end{array}$} & \multicolumn{1}{c|}{$\begin{array}{c}\text { Not a } \\
\text { constraint }\end{array}$} \\
\hline Lack of water & $298(78.4)$ & $67(17.6)$ & $15(3.9)$ \\
lack of effective channel for cassava effluent & $245(64.5)$ & $103(27.1)$ & $32(8.4)$ \\
Lack of effective disposal method of cassava peels & $169(46.9)$ & $98(25.8)$ & $113(29.9)$ \\
Lack of labour & $305(80.3)$ & $59(15.0)$ & $18(4.7)$ \\
Unstable price of cassava products especially gari & $269(70.3)$ & $101(26.6)$ & $12(3.2)$ \\
\hline
\end{tabular}

NOTE: Figures in parenthesis are in percentages

* Multiple response given 


\section{REFERENCES}

1. Bruijin-De GH and LO Fresco The importance of cassava in World Food Production. Netherlands Journal of Agricultural Science 1989; 37(5): 21-34.

2. Cock JH Cassava: A new potential for a neglected crop. Wet view press, Boulder and London. 1985: 64-69.

3. Hahn SK and J Keyser Cassava: A basic food of Africa. Outlook on Agriculture 1985; 14 (2): 96-98.

4. Omueti $\mathbf{O}$ Traditional cassava processing and improved management practices. In: Proceedings of a workshop on promotion of improved management technologies aimed at reducing occupational and environmental hazards associated with cassava processing in Ogun, Ondo and Oyo States 2004: 1-5.

5. Oyewole OB The powers at the roots: Food and its microbial allies. University of Agriculture, Abeokuta. Inaugural lecture series 2002; No.15: 2-6.

6. Fellows $\mathbf{P}$ Traditional food processing for profit. Intermediate technology publications, United Kingdom. 1997.

7. Oboh G Management of occupational hazards associated with traditional method of cassava processing. In: Proceedings of a workshop on promotion of improved management technologies aimed at reducing occupational and environmental hazards associated with cassava processing in Ogun, Ondo and Oyo States 2004: 11-19.

8. Oyegbami A Social hazards associated with cassava processing and control management practices. In: Proceedings of a workshop on promotion of improved management technologies aimed at reducing occupational and environmental hazards associated with cassava processing in Ogun, Ondo and Oyo States 2004: 33-37.

9. Adebayo K and OD Salahu Processors perception of the effect of the presidential initiative on cassava in the industry in Ogun state. Nigerian Journal of Rural sociology 2007; 7 (1\&2): 25-38. 